\title{
Breve presentación de los textos complementarios de Ding und Raum. Vorlesungen 1907 de Edmund Husserl.
}

\section{Luis Alberto Canela Morales}

\section{Introducción}

En el tomo XVI de la serie Husserliana, Ding und Raum. Vorlesungen 1907,'1 se encuentran editadas las lecciones que versan sobre la cosa física y la percepción. Están precedidas por Die Idee der Phänomenologie. Fünf Vorlesungen que también fueron lecciones dictadas por Husserl en la Universidad de Gotinga del 26 de abril al 2 de mayo de 1907. Estas tenían como objetivo, entre otros, meditar sobre la reducción fenomenológica y explicitar la incursión en el tema de la constitución o "de la dilución del ser en la conciencia". ${ }^{2}$ En ese sentido, La idea de la fenomenología es un preámbulo para Cosa y espacio, y aunque Husserl no vuelve en esta obra sobre los problemas tratados en La idea de la fenomenología, sí supone su conocimiento, pues,

\footnotetext{
${ }^{1}$ Husserliana XVI, Hrsg, von Ulrich Claesges, The Hague, Martinus Nijhoff, Netherlands, 1973. Las lecciones sobre la cosa física pertenecen al ciclo "Fragmentos capitales de la fenomenología y de la crítica de la razón". Se encuentran entre la carpetade manuscritos pertenecientes rotulados con las siglas F I 13, que a su vez se enmarcan en las lecciones del semestre de invierno de 1906-1907 intituladas "Introducción a la lógica y crítica del conocimiento", manuscritos F I 10, F I 16 y F I 25, con algunas hojas de F I 7 y F I 17. Manuscritos citados por el editor alemán de Ding und Raum, pp. xviii.

2 Edmund Husserl, La idea de la fenomenología, Intr., del editor alemán, pág. 15. [Hua II, viii, Einleitung des Herausgebers]
} 
justamente, Cosa y espacio es un seguimiento o, mejor dicho, una investigación que retoma el marco metodológico estudiado, además de que pone en "práctica" los conceptos que arrojó La idea de la fenomenología.

Con lo anterior, es de suma valía analizar y comentar las tesis principales de Cosa y espacio, no sólo por su valor histórico, sino también por el profundo tratamiento fenomenológico que, a propósito de la espacialidad, Husserl desarrolla. A mi juicio, creo que en Ding und Raum se pueden encontrar dos enclaves fundamentales. Uno de ellos, el más conocido, señala cómo estas lecciones exponen algunas tesis importantes sobre la corporalidad y la espacialidad. En efecto, estas lecciones anticipan varias de las tesis localizadas en Ideas II e Ideas III; planteamientos básicos como el de las cinestesias y el punto cero del cuerpo ya son analizados en Cosa y espacio. El segundo enclave muestra cómo en Ding und Raum ocurre el "giro temático" que va del espacio geométrico a la corporalidad. Dicho de otro modo, se tiene muy presente la idea de que estas lecciones son un "cambio de orientación" (temático), mismo cambio que posibilita la comprensión de porqué el estudio de la tríada: espacio geométrico, espacio intuitivo, corporalidad, (que constituyen el programa husserliano de una fenomenología de la percepción) comienza ponderando el espacio geométrico y el espacio intuitivo, para después volcarse sobre el análisis de la corporalidad. Sin más, comienzo la presentación de cada uno de los apéndices de dicha obra. 
Apéndice I. Contiene las marcas y anotaciones que fue haciendo Husserl durante y después de la elaboración de estas lecciones. Después de revisarlas a detalle, decidí no integrarlas porque no alteran el contenido de esta exposición.

El apéndice II de Ding und Raum (probablemente de 1910), muestra un examen fenomenológico estático de la cosa percibida a un nivel constitutivo muy básico y así prospectar una serie de estratos fundados unos en otros. Husserl distingue ahí cuatro tipos de estratos que confluyen en la constitución de la cosa dada en la percepción externa:

Consideramos a la cosa física como lo dado en la percepción, es decir, en la síntesis continua de percepciones, que llamamos simple experiencia (schlichte Erfahrung) (en contraposición a las determinaciones conceptuales del objeto de manera más perfecta en forma de la ciencia natural).$^{3}$

La cosa en cuanto objeto de la experiencia simple y llana, le subyacen tres estratos: el esquema temporal, el esquema espacial y la plenitud sensible del esquema espacial.

${ }^{3}$ Hua XVI, 341. 
1.- El esquema temporal. La cosa tiene una determinada localización temporal, una duración, es, pues, una unidad de duración. La cosa espacial es una res temporalis.

La cosa es una unidad de la duración; ella "tiene una duración" y tiene su determinada localización en el tiempo. Su duración es diferente de la duración que ella podría tener si existiera en otro punto del tiempo. La duración determinada como duración de la cosase llenacon lasdeterminaciones de la cosa en unidad, que precisamente conforman la cosa como contenido temporal (in abstracto, prescindiendo del lugar absoluto en el tiempo como forma universal),y precisamente el segmento entero de duración posee un contenido cósico, de tal modo que cada punto temporal de este segmento (un "punto individual") tiene suyo. ${ }^{4}$

2.- Esquema espacial. De la unidad entre la figura y el lugar de la cosa sensible, surge el esquema espacial, que se constituye como una determinada forma geométrica. La cosa es una res extensa.

Lo mismo aplica al esquema espacial de la cosa. En cada punto temporal de su duración, la cosa física ocupa y llena un sector determinado "de"

\footnotetext{
${ }^{4}$ Hua XVI 341. En Ideas II, § 12, aparece esta caracterización, pero ahora con mayor exactitud: “Todo ser cósico está temporalmente extendido; tiene su duración y con su duración se ubica de manera fija en el tiempo objetivo. Tiene así su duración un sitio fijo en el tiempo único del mundo, que es una forma general de existir para toda cosidad. Todo lo que la cosa en otros respectos "es", conforme a cualquier otra determinación esencial que le convenga, lo es en su duración, lo es con la más precisa determinación de un cuándo". p. 57, [Hua IV, 28].
} 
espacio. Este sector del espacio es una determinación constitutiva “interna" de la cosa física, es decir, ella tiene una estructura determinada (el mejor nombre para esto es el esquema espacial, cuerpo geométrico) la cual, como geométrica, puede tener la misma estructura en diferentes lugares (en diferentes posiciones). ${ }^{5}$

3.- El fantasma de la cosa. De la necesaria unidad de estos estratos surge lo que Husserl denomina el "fantasma de la $\cos a$ ", el esquema sensible o la plenitud sensible de la cosa.

El esquema espacio-temporal junto con su plenitud sensible da siempre una unidad que podemos llamarla el fantasma de la cosa (Dingphantom) (también el esquema completo, también el esquema sensible). ${ }^{6}$

El esquema sensible o fantasma de la cosa es la figura corpórea sin determinaciones o cualidades materiales, todavía no es la cosa sensible, porque las cosas sensibles ya

\footnotetext{
${ }^{5}$ Hua XVI, 341. Nuevamente, en el $\S 12$ de Ideas II, aparece esta idea con algunos cambios: "Además, todo ser cósico tiene su puesto en el espacio del mundo, y este puesto es relativo a todo otro ser cósico y alterable por principio. Es algo movible en el espacio merced a su extensión corpórea, que le es esencialmente inherente y exclusivamente propia, la cual puede alterar constantemente su posición en el espacio". p. 58, [Hua IV, 28].

${ }^{6}$ Hua XVI, 343. Siguiendo en esta misma línea, el inciso "b" del §15 de Ideas II clarifica, por mucho, la cita extraída deDing und Raum. Afirma Husserl: "Decimos que la esencia de una cosa comprende un ESQUEMA SENSIBLE, y con ello entendemos este armazón básico, esta figura corpórea ("espacial") con la plenitud extendida sobre ella. La cosa que aparece en reposo y cualitativamente inalterada no nos "MUESTRA" más que su esquema, o más bien la apariencia, mientras que, ciertamente, está a la vez "APREHENDIDA" como material". p. 67, [Hua IV, 37].
} 
en el sentido pleno, están constituidas a través de un último estrato: las propiedades naturales o causales de la cosa.

4.- Las propiedades causales (naturales) de la cosa. Son las propiedades de la cosa en relación con las demás cosas. Husserl utiliza palabras como "habilidad", "disposición", "capacidad o fuerza"7 para caracterizar algunas de tantas propiedades que puede tener la cosa. Son las propiedades las que suscitan un cambio en ella, sin que por ello se altere su identidad. En suma, la cosa es una res materialis.

La cosa sensible, en estricto sentido, el fantasma, el esquema sensible es el portador de las determinaciones causales, capacidades: esto en el sentido de la pura experiencia perceptiva (perzeptiven). ${ }^{8}$

El fantasma de la cosa es irreal, su paso a lo real (real) se dará a través de la materialidad, que no es otra cosa más que las propiedades causales o naturales de los objetos. ${ }^{9}$ Hay que apuntar que muchas de las propiedades naturales o causales,

\footnotetext{
${ }^{7}$ Hua XVI, 343.

sídem.

${ }^{9}$ En el anejo XII de Ideas II enfatiza lo que aquí acabamos de comentar: "A la cosa en cuanto naturaleza. Ella es como tal sustancia intuitiva en el sentido de una unidad intuitiva de propiedades reales. Es en lo más bajo cosa sensiblemente intuitiva que se exhibe mediante esquemas. El esquema es aquello en ella que es dado mediante apercepción sensible propia. Sobre ella se edifica la apercepción causal: la cosa de los sentidos es captada como lo idéntico de maneras de comportamiento. Por vez primera sobre la base de esta apercepción causal designamos la cosa como real, y aquí tiene su origen el hablar de la realidad". pp. 392-393, [Hua IV, 340].
} 
como por ejemplo, la "fuerza o la tensión entre una cosa y otra" no son perceptibles; en cambio, el esquema espacial-temporal, ese sí podemos intuirlo:

Y además, la distribución de una propiedad a través de la posición espacial y partes espaciales es intuible para la esfera de los esquemas, esto no es así para las nuevas determinaciones. No vemos en sí la fuerza difundida; la pensamos y esquematizamos a lo mucho en imagen. ${ }^{10}$

Es evidente, afirma Husserl, que las propiedades naturales o causales presuponen o se fundan en el fantasma de la cosa, en los tipos esquemáticos. ${ }^{11}$ Las propiedades naturales son, pues, momentos no-independientes del fantasma de la cosa.

Apéndice III (al §20). El apéndice número tres, posiblemente del año 1907, se dedica a explorar el problema de las notas espaciales, especialmente el color. $\mathrm{Si}$ partimos de la idea de que todas las notas espaciales (forma, figura, etc.,) están en correspondencia con la continuidad de sus cualidades -lo que significa que están íntimamente enlazados-, es claro que el color y su extensión son un buen ejemplo de esto último:

\footnotetext{
${ }^{10}$ Hua XVI, 343. Nuevamente en el segundo tomo de Ideas, Husserl se muestra más contundente: “El GOLPE Y LA PRESIÓN NO pueden propiamente ser VISTOS; puede verse solamente lo que con ellos ocurre en el espacio y en la figura. Tampoco LA PRESIÓN, LA TENSIÓN, LA RESISTENCIA pueden experimentarse mediante el mero tocar". p. 69, [Hua IV, 39].

${ }^{11}$ Hua XVI, 343.
} 
Los matices-color transcurren eo ipso junto con los perfiles espacialesporque el color recubre (überdecken) la forma y la consistencia (Festigkeit) en la continuidad de los perfiles-forma, también condiciona una consistencia en los matices-color. Empero, todo esto aun no es suficiente; algo mas está implicado. ${ }^{12}$

A cada perfil ${ }^{13}$ o escorzo perceptivo (extenso) le corresponde un momento de coloración. Si consideramos un escorzo perceptivo (individual) como un todo (unitario), entonces, se entiende que a una extensión "pre-empírica" (protoobjetiva) le corresponde un color "pre-empírico", pues a cada parte extensiva le pertenece un momento de color. La unidad de todos los momentos de color, junto con su respectiva extensión, constituye la unidad de la coloración total en correspondencia con la unidad extensiva total (el objeto percibido).

Lo que Husserl afirma es que extensión y color son momentos noindependientes, y lo son no por mera experiencia fáctica o de convenio, sino porque en ellos existe una necesidad ideal y objetiva que impide que puedan representarse por separado. Naturalmente, la modificación de uno no implica la modificación del otro. Por eso, bien apunta Husserl:

\footnotetext{
${ }^{12}$ Hua XVI, 346.

${ }^{13}$ En esta última parte cuando Abschattung se refiera a una "parte" del objeto será traducido (como lo he venido haciendo) por "escorzo" o perfil", pero cuando hablemos del color se traducirá como "matiz". Esto para diferenciar correctamente entre uno y otro rasgo característico de la cosa.
} 
El orden de la forma (Ordungsform) puede ser recubierta por diferentes colores: la misma extensión, diferentes colores. ¿También mismos colores y diferentes extensiones? En cierto sentido, si; y en cierto sentido, no. Las diferentes extensiones pueden tener el mismo color unitario, es decir, cada una de ellas tiene en todas sus partes "el mismo color". La misma cualidad-color extendida uniformemente sobre cada parte y del mismo modo uniformemente en otras extensiones. ${ }^{14}$

La cita es clara y muestra dos cosas interrelacionadas: primero, cuando percibimos una "mancha azul" y fantaseamos que podemos hacerla tan grande como para cubrir una mesa de billar, esto no implica, de ningún modo, que el azul se haga más azul, en cambio, la inversa sí procede, pues el color (el color que sea) necesita una extensión para ser un color intuido, para ser visualmente percibido. Debe poseer un mínimo de extensión para ser visto. Segundo, como el color es un momento no-independiente de la extensión, puede esto significar que la esencia del color (su género) es uno y el mismo en diferentes manifestaciones, por ejemplo el "amarillo" en una hoja de papel o en un autobús, claro, cada manifestación tiene su propia "especie" de ese color:

Colores idénticos (esencialmente idénticos, pero individualmente diferentes) estánsólo “individualizados"a travésde lugares diferentes, pero los lugares diferentes no son individualizadosa través de los

\footnotetext{
${ }^{14}$ Hua XVI, 346.
} 
colores, los cuales, en efecto, pueden cambiar [...] El lugar no obtiene su orden a través de los colores, sino los colores través de los lugares. ${ }^{15}$

Según Husserl, es en los lugares (o espacios) donde se "individualizan" los colores, siendo que estos, en esencia, son los mismos. El color es uno, lo coloreado es múltiple. Párrafos atrás mencionábamos el vínculo entre los matices de color y el color unitario, dicho de otro modo, entre la discontinuidad de los matices de color y la uniformidad del color percibido. Basado en este enlace, Husserl confirma que la discontinuidad no es caótica, sino más bien ordenada a la organización del color unitario. Así, las cualidades de color, las variadas cualidades de color, tan diversas como los mismos escorzos perceptivos, se tornan "una" pero no por obra propia, sino por la unidad del objeto, constituida a su vez por la conciencia sintética de identidad.

Los matices de color dentro de una cosa pasan de uno a otro. Imaginemos frente a nosotros un cubo morado girando sobre su propio eje de un lado a otro. A cada cambio, el color se va matizando, es decir, habrá momentos en los cuales nos "parecerá que el morado es más oscuro, en otros más claros, con más brillo, etc." A pesar de esto, los matices de color, tan variados y múltiples, están unificados en un solo color unitario y uniforme, en este caso, el morado:

${ }^{15}$ Hua XVI, 347. 
Una coloración pasa sobre otra coloración; "pasar sobre" significa aquí, especialmente, que ambos sonmatices de un mismo color objetivo, uno de los perfiles viene a la aparición al mismo momento y llega a integrarse completamente en el aparecer: por ejemplo, el mismohexaedro visto desde dos diferentes ubicaciones. ${ }^{16}$

Lo expuesto aquí es cómo la discontinuidad propia de cada matiz-color de un objeto percibido, presenta el color objetivo, o lo que es lo mismo, cómo se integra en ellos la coloración objetiva unitaria. En otra palabras, lo que Husserl expresa aquí es la diferencia entre el color objetivo y el color subjetivo (léase, vivido fenomenológicamente). El cubo morado del ejemplo anterior, en tanto color objetivo, se presenta como un color unitario y uniforme, se nos da como uno y el mismo morado, no es más morado en unas partes y en otras no, de hecho, si alguien me preguntará por el color del cubo que tengo en las manos, diría morado y no "matices de morados", es más, cuando lo compré así lo pedí, como un "cubo morado" y no como un "cubo que parece morado si lo pongo a la luz y oscuro si no hay algo que me ilumine". ${ }^{17}$ En cambio, el color subjetivo, ese sí está sujeto a la gradación de las sensaciones cromáticas subjetivas, regidas a su vez por las leyes de la perspectiva. Por ejemplo, si nos enfocamos en el color tal como se nos aparece en este mismo cubo morado, nos percataremos de las "variaciones" que el aparecer visual del color morado manifiesta en sus diversas gradaciones: visto a contraluz el

\footnotetext{
${ }^{16}$ Hua XVI, 347-348.

${ }_{17}$ Podemos dar como contraejemplo un cubo de varios colores, uno por cada lado. Pero aun así, el ejemplo no es válido, porque Husserl se refiere a la uniformidad con la que el color recubre el objeto, ningún color se encima uno en el otro. Cada uno tiene su propia extensión y uniformidad.
} 
morado me parece un tanto más "claro" o por el contrario, si le muestro este hexaedro a alguien por la noche, sin ningún tipo de luz que nos ayude a observar, el morado definitivamente se me aparece como más oscuro, casi negro.

Este problema es crucial y antes de terminar esta exposición me referiré a él. ${ }^{18}$ El cambio al que se alude aquí, es un cambio en la situación objetiva y no así en la cosa, es decir, que está producido por el movimiento de mi cuerpo y de los cambios en la iluminación. Los cambios en la iluminación afectan lo percibido de tal modo que éste adquiere una nueva modificación -no una nueva cualidad, pues la luz no es propiedad de los objetos-. Por ejemplo, si ilumino con una luz azul una hoja blanca, esta "adquiere" una tonalidad azulada, lo mismo si ilumino la misma hoja blanca con una luz amarilla, esta se "vuelve" amarillenta. Lo que ocurre aquí es un cambio en la situación objetiva o "estado de cosas" que "abarca no sólo la cosa directamente, sino un segundo objeto muy peculiar, cuyos cambios afectan a la percepción de dichas cosa directamente percibida" (Fernández Beites, 1999:498), este segundo objeto tan peculiar es la luz. La luz más un estado de cosas genera cambios en el modo como la cosa coloreada aparece.

El color objetivo de una esfera roja, su color "propio", se obtiene si prescindimos de irradiaciones excesivas o mínimas que la alteren, mucha luz genera un matiz de rojo, lo mismo que una luz muy tenue. La modificación debida

\footnotetext{
18 En esta última parte seguiremos la exposición de Fernández Beites (1999:497-503), pero iremos añadiendo algunos puntos.
} 
a la luz puede ser tal, que cuando transito por una calle muy oscura simplemente los objetos no son "perceptibles" de modo claro, se ven "borrosos", "oscuros" y en la mayoría de los casos sin color alguno.

A juicio de Fernández Beites, las modificaciones más importantes debidas al cambio de luz son dos: las sombras y los brillos. ${ }^{19}$ La sombra "consiste en la desaparición parcial de la luz debido a la interposición de algún objeto" y los “brillos se producen por el reflejo de la luz sobre una superficie (Fernández Beites, 1999:499-500).

Hablemos de las sombras. Estas no se me dan en "escorzos", se me dan siempre completas, la sombra que produce cualquier objeto se me da forma plena, es decir, ninguna sombra se me aparece como "de frente" o por "detrás", con tales y cuales cambios. Es más, si giramos nuestro cuerpo, la sombra se queda siempre a mi lado o detrás de mí (todo depende desde donde esté incidiendo la luz), mejor aún, no "aparece" de modo tridimensional, sino sólo bidimensional, por lo que no tiene un "detrás de" o una "profundidad". ${ }^{20}$ Por si esto fuera poco, cuando cierro las cortinas de mi balcón puedo notar que las sombras que producen las cortinas hacen que todo lo que está dentro de mi cuarto adquiera una tonalidad más oscura.

\footnotetext{
${ }^{19}$ Dado que las modificaciones debidas a la sombras dependen de la luz, hablaremos de ellas en su sentido proyectivo. Para un análisis más detallado de esta fascinante modificación en lo percibido Cfr. González Guardiola, (2010).

20 Aún en el hipotético y fantástico caso que pudiéramos separarnos de nuestra sombra (como sucede en el cuento para niños, Peter Pan) sería imposible ver un "detrás" de la sombra.
} 
Los brillos. Ellos son un caso bastante paradigmático en lo percibido, pues ocurren cuando la luz incide en la cosa percibida acentuando un tono particular. El objeto percibido se ilumina de tal modo que es posible apreciar en él un matiz más cargado, justamente, con "brillos". Por ejemplo, si mientras camino por las calles de la ciudad voy girando de un lado a otro una esfera roja, notaré, entonces, que aparecen y desaparecen constantemente tonos "brillantes" en ella, inclusive puedo ir "jugando" con los brillos viendo cómo este se va moviendo si giro la esfera hacia la derecha o hacia la izquierda; así pues, el "color brillante se abre paso", adquiere una nueva modificación que depende del movimiento y la orientación de la luz, es un cambio producido por la variación de la posición.

Todas estas determinaciones, explicitan la profunda y evidente correlación de los escorzos perceptivos con la objetividad del color. El color subjetivo no deja de tener una relación con el color "objetivo" pues forma parte de él, aquél cubre al objeto de modo "uniforme", cubre su espacialidad objetiva. Es por ello que en el lenguaje cotidiano hacemos referencia o señalamientos sobre el color objetivo, como cuando decimos ipásame aquella pelota gris! El color grisáceo le "pertenece a la cosa como color objetivo", los matices de gris pertenecen a los escorzos perceptivos en el sentido fenomenológico del término, ellos recogen la diversidad de matices y variaciones de color que puede tener una situación objetiva. A diferencia del color subjetivo, el color objetivo no varía frente a las circunstancias o entornos, él no sufre cambios, esto es, si es de noche o si tengo que usar lentes o si hay neblina, no significa que el color objetivo se tenga que adecuar a estas necesidades, más bien el color objetivo sigue siendo el mismo, los que no 
percibimos bien somos nosotros en todo caso. En resumen, el análisis fenomenológico del color desarrolla una descripción más precisa del "aparecer" de la cosa coloreada y del modo como la percibo.

Apéndices IV-VIII. Estos apéndices tienen dos temas o problemas en común, a saber, los sistemas cinestésicos (y sus nexos motivacionales) y las cualidades que llenan el espacio. Teniendo en mente estos tópicos comentaremos estos brevísimos apéndices; es necesario precisar que la mayoría de ellos son del año de 1916.

Lo que podemos denominar la "primera parte" de Cosa y espacio, trata sobre la constitución del espacio visual bidimensional. Desde esta (insuficiente) doble dimensión se da la oportunidad de analizar el sistema cinestésico oculomotor de "monocularidad" y "binocularidad". De cierto modo, y siguiendo a Ulrich Claesges, parece ser que con esto último avanzamos a la ampliación -a través de la cinestesia de "acomodación"- del desplazamiento de los ejes oculares. ${ }^{21}$ Sobre el análisis de lo que debe de entenderse como tipo oculomotor, Husserl afirma lo siguiente:22

1) Es lo motivado "bidimensionalmente", una "multiplicidad" $(M)$ con posición cero y cero direcciones. Donde $(M)$ quiere decir multiplicidad

\footnotetext{
${ }^{21}$ Cfr. (Claesges, 1964: 79 y ss.)

22 Hua XVI, 349.
} 


\section{ARTÍ́CULOS}

cinestésica (o de movimiento) bidimensional vinculada a la multiplicidad de tiempo unidimensional.

2) La multiplicidad del campo sensorial (Sinnesfeld-Mannigfaltigkeit) bidimensional opera con una separación entre la "localidad" (Lokalität) y la cualidad (Qualität), o entre "figura" y "cualidad". Dicho de otro modo, en el campo sensorial bidimensional siempre encontramos una "posición" (Lage) y una figura (cualificada). Con la letra (S) Husserl representará lo anterior.

3) El tipo oculomotor es una multiplicidad que, aunque se va incrementando, tiene un límite bidimensional, además, "el campo pre-empírico $\mathrm{M}$ es un sistema de lugares fijos y no admite ningún tipo de asociación C- $M^{\prime \prime}$ (Petitot, 2000: 357).

Estos tres puntos se vinculan a las leyes que conectan o asocian las secuencias temporales de la multiplicidad-M y la multiplicidad-S, así como las condiciones que nos permiten distinguir entre posiciones ciegas, puntos ciegos, y cosas visuales. Para que nos quede aún más claro lo anterior, procedamos, como Husserl lo hace, analizar la visión monocular.

\section{Monocularidad}


Un sistema cinestésico monocular se coordina con el campo sensorial visual como un campo de sentido de sensaciones visuales; es, además, un sistema cinestésico de multiplicidad bidimensional, lo único que en él puede realizarse o actualizarse son puntos y líneas sucesivas. Más allá del plano visual lineal y puntual no hay nada, es decir, no hay profundidad, por lo que todas las imágenes aparecidas en el campo visual se hayan sujetas a las reglas bidimensionales; por último, el campo visual monocular es un campo irreal pues se presenta sólo en planos abstractos.

Hemos dicho que este sistema visual es una multiplicidad bidimensional a la que podemos representarnos con la idea de un plano $^{23}$ con un punto cero y con puntos de direcciones coordinadas (arriba, abajo, derecha, izquierda). Con base en esto, encontramos por lo menos dos leyes que rigen dicho campo:

A) "Ley: cada cuerpo sensorial visual (Sehsinnkörper) "reposa", presenta reposo, o presenta un movimiento". ${ }^{24}$ Un cuerpo que no está en reposo o en movimiento es un cuerpo aparente o un pseudo-cuerpo (Scheinkörper), es decir, un punto ciego. Un cuerpo sensorial visual que está en reposo significa que tiene un detenimiento cinestésico duradero o pasajero. En geometría plana esto es equivalente a decir que obtenemos un resultado igual a cero en los ejes horizontales y verticales: $(f(x, y)=0)$.

\footnotetext{
${ }^{23}$ Hua XVI, 350.

${ }^{24}$ Ídem.
} 


\section{ARTÍCULOS}

B) "Ley: el movimiento exhibido de cuerpo sensorial visual (Sehsinnkörper)".${ }^{25} \mathrm{El}$ movimiento se presenta cuando el cuerpo sensorial visual se desplaza (Wandert) en el campo visual, sin que tenga lugar un movimiento ocular. El desplazamiento puede ocurrir en paralelo al movimiento ocular o en sentido contrario.

La idea principal aquí es que la monocularidad junto con el campo sensorial visual y el sistema motivacional de movimientos es una condición de posibilidad mínima para constituir el espacio tridimensional.

\section{Binocularidad}

Por un lado tenemos que la visión ciclópea no es posible como visión espacial tridimensional, pues aunque los campos sensoriales visuales individuales (nos referimos a cada ojo por separado) pueden actuar cada uno "por su lado" -teniendo una acción propia y dividiendo un campo monocular L y un campo monocular $\mathrm{R}-$, sólo entre ambos constituyen un campo visual. Su dependencia funcional es justo su integración en un campo ocular que presenta las siguientes maneras de ser analizado: 
1) Una imagen en el campo ciclópeo puede permanecer idéntica sin cambios en el contenido cuando exista por lo menos un campo ocular abierto, pero los dos tienen idénticamente el mismo objeto.

2) Es posible una combinación. La imagen binocular se desvía de la imagen monocular mientras retiene la similaridad de la imagen. Esto trae consigo una ampliación y una contracción de la figura y su cumplimiento.

3) Son posibles las dobles imágenes (doppelte Bilder), esto es, ver una imagen a través de otra por medio de una inversión.

Con el sistema de movimientos oculares coordinado con la motivación cinestésica obtenemos un sistema de objetos y puntos objetivos constituyendo así un campo tridimensional. Dicha coordinación trae consigo que una multiplicidad bidimensional sea una multiplicidad transicional que recorre el campo oculomotor.

Retomemos el punto anterior, el del papel de la motivación cinestésica. La imagen se somete al "si-entonces", es decir, "si realizo tal cosa, ocurre tal otra". De nueva cuenta aparece la correlación entre la apercepción y la motivación. A estas alturas resulta claro cómo las secuencias cinestésicas motivan las secuencias de imágenes -pero no a la inversa-, pues son ellas un flujo continuo de "predelineamientos" que buscan su cumplimiento intuitivo; como tal, constituyen un sistema de posibilidades que son libremente generadas y ordenadas. En este 
punto ocurre un fenómeno muy particular, se trata del fenómeno- $\phi{ }^{26}$ que Husserl describe como unitario y secuencial. ${ }^{27}$

El apéndice $V$ (al § 54) retoma los planteamientos sobre la trascendencia de la cosa y su darse inadecuadamente. Como ya lo hemos reiterado en varias ocasiones, la inadecuación es propia de la cosa, justo por ello se da en perfiles. Empero, hay un momento de adecuación en la inadecuación, y con esto nos referimos a la identidad en la continuidad de la cosa, esto es, que en la conciencia el "haz de rayo de intenciones provee unidad penetrando las imágenes" 28 correspondientes. Esto también puede ser interpretado del siguiente modo: el rayo intencional no desaparece, la que "desaparece" o "cambia" es la imagen, es decir, ocurre una nueva exhibición; hay que recordar que a cada $C_{1}$ le corresponde unaI 1 102 en $\mathrm{T}_{1}$, como bien apunta Husserl, "un rayo intencional de un nuevo tipo surge motivado por el movimiento-C". ${ }^{29}$

\footnotetext{
${ }^{26}$ El fenómeno- $\phi$ al que posiblemente alude Husserl es un proceso que fue estudiado y definido por Max Wertheimer en 1912 (el apéndice que ahora estudiamos es de 1916). Según Wertheimer (que también estudió con Stumpf en 1900) el fenómeno- $\phi$ es una ilusión óptica donde se "crea" un flujo de movimiento (continuo y simple) a partir de una serie de imágenes o figuras estáticas. Dicho fenómeno consiste en que podemos percibir el movimiento "donde realmente no lo hay" y lo "vemos" porque basados en estas series sucesivas de imágenes, figuras o impulsos luminosos completamos los pequeños fragmentos del mismo, vamos "completando" la secuencia del mismo. La frecuencia a la que se somete este fenómeno tiene determinada velocidad de imágenes por segundo, de lo contrario el "movimiento aparente" no podría percibirse. El movimiento aparente parece ser percibido cuando "no hay ningún estímulo" que se mueva de "verdad", que no cambie su posición, en resumen para que el fenómeno- $\phi$ se lleve a cabo debe contar con una serie de imágenes (simultáneas y secuenciales) y una determinada frecuencia temporal.

${ }^{27}$ Hua XVI, 360.

${ }^{28}$ Hua XVI, 357.

${ }^{29}$ Ídem.
} 
Hay que tener presente cómo en buena medida lo anterior tiene relación con el problema del color al que en otros momentos nos hemos referido; en efecto, sólo en sentido abstracto (como en los planos) podemos considerar al cuerpo físico como una mera estructura, pero ¿el color puede pensarse sin cubrir una extensión? La respuesta como sabemos es negativa, el color siempre acompaña a la extensión, la recubre, su determinación estriba en la determinabilidad de lo espacial, aunque atienda al color en su momento cromático subjetivo o lo atienda en su uniformidad siempre se presenta como cubriendo un espacio. El color es un color estructurado y extendido, como bien apunta Husserl: "una superficie está coloreada simple y homogéneamente si todos sus puntos tienen la misma coloración; cada coloración consiste en coloraciones puntuales". ${ }^{30}$ Justo en esta línea podríamos analizar, brevemente, el problema del "espacio vacío" (Leerer Raum); ${ }^{31}$ el problema a resolver aquí es la posibilidad de "ver" un espacio vacío, es decir, un espacio no-objetivo. De entrada esta posibilidad será rechazada por Husserl porque queda claro que el espacio es continuo; existe en él una serie o un nexo continuo de puntos que se extienden objetivamente. En todo caso, el espacio vacío puede ser entendido como espacio potencial para el desplazamiento de los objetos, pues:

El espacio tiene, por lo tanto, el carácter de la potencialidad (Potentialität,), porque es correlato de un sistema de disponibilidades (Vermöglichkeiten). La potencialidad del espacio está realizada a través de

\footnotetext{
${ }^{30}$ Hua XVI, 363.

${ }^{31}$ El apéndice VII (al §76) trata sobre esto.
} 


\section{ARTÍ́CULOS}

un fantasma como forma en una posición en él. Esta realización de parte de los correlatos corresponde a la realización en el sistema cinestésico mismo.(Claesges, 1964:82)

El espacio en el que piensa Husserl es el plano euclidiano que no admite rupturas en su homogeneidad. De hecho, lo que vemos es una multitud de puntos uniformemente distribuidos en el espacio visual, remarcamos "uniformemente distribuidos" y que a su vez se localizan en diferentes "localidades y profundidades". 32

A final de cuentas, el punto se relaciona con la intuición espacial que cree poder observar el "vacío" en el espacio, confundiéndolo con el "espacio de aire" entre una cosa y otra. Por ejemplo, el espacio vacío entre un libro y otro en un librero, siendo que esto no es más que el espacio "hueco", pero no vacío; según Husserl, el espacio visual es constante y homogéneo, no tiene rupturas, la totalidad de la dación de las cosas es expansiva por lo que no admite puntos "sin nada". Sólo en sentido abstracto los conceptos de lugar y espacio podrían ser analizados como "vacíos", pero en sentido estricto esto no podría ser. ${ }^{33}$

\footnotetext{
32 Hua XVI, 361.

${ }^{33}$ Hua XVI, 262.
} 
Apéndices IX-XII. Ulrich Claesges analiza en el §9 de su Edmund Husserls Theorie der Raumkonstitution, la posibilidad de una ciencia del espacio nomatemática, valga incluso decir no-geométrica en el sentido más científico de la palabra. Cabe el cuestionamiento del porqué de esta aseveración. ${ }^{34}$ El motivo es el siguiente: la geometría como ciencia del espacio es también una ciencia matemática exacta y, como tal, es una ciencia que analiza el mundo objetivándolo, lo cual no quiere decir que estos análisis (netamente científicos) vayan por un camino errado, pues como bien apunta Welton: "las ciencias no apuntan el mundo equivocadamente, sino 'objetivamente'" (2006:99), es decir, con el mero carácter de objeto material, y de lo que se trata aquí es de analizar aquello que hace posible la aparición de los objetos.

Ante esta imposibilidad de utilizar, previamente, una ciencia dedicada al análisis espacial, el interés de Husserl se volcará a validar (fenomenológicamente) la geometría como una ciencia eidética capaz de dar cuenta de la constitución (o construcción) pura del espacio físico, de tal modo que obtengamos con ella una esencia del espacio morfológica y exacta, una espacialidad pura como forma fundamental y universal de lo cósico, donde efectivamente pueda notarse que "la

\footnotetext{
${ }^{34}$ A propósito de los análisis de Ulrich Claesges, resulta que en su texto Edmund Husserls Theorie der Raumkonstitutionk, en el §18 utiliza, para explicitar la tridimensionalidad del espacio, las investigaciones de Oskar Becker, a quien ya hemos aludido junto con sus Beiträge zur phänomenologischen Begründung der Geometne und ihrer physikalischen Anwendungen publicadas en el anuario de 1923. Las investigaciones de Becker y Husserl, tal como las presenta Claesges, coinciden muchísimo, a tal grado de ser complementarias una y otra, con la diferencia de que el trabajo de Becker es de una hondura matemática impresionante. Cabe señalar que el trabajo de Claesges es notable no sólo por la reconstrucción de la fenomenología de la espacialidad con base en los manuscritos D y otros textos de Husserl, sino porque es pionero en este campo.
} 
objetividad del apriori exacto del espacio es resultado de una desconexión metódica de todo lo relativo-subjetivo" (Claesges, 1964:46) que pertenece al campo de hechos.

Estoy convencido de que esto último es el hilo conductor de los cuatro apéndices restantes de Cosa y espacio. Esto no sólo nos obligaría a tener presente lo hasta ahora enunciado, sino que también abre la posibilidad de vincular el análisis fenomenológico con las geometrías de Riemann y Euler a quienes Husserl cita en varias ocasiones. El desarrollo de este último apartado redondeará, en la medida de lo posible, las tesis hasta ahora analizadas.

La mención de Euler no es gratuita, pues es muy probable que el geómetra suizo haya influido en Husserl a nivel de su análisis de la geometría analítica, cuyos antecedentes pueden rastrearse hasta Descartes y Fermat. Asimismo, la sistematización que realizó Euler de la geometría plana y tridimensional -que también tuvo aplicaciones dentro de la teoría de las secciones cónicas- supone una solución a problemas geométricos mediante el sistema de "coordenadas" y "gráficas". En buena medida lo que Husserl llama "traslación" tiene su equivalente en la teoría de Euler cuando él analiza las diversas posibilidades del cambio de coordenadas al cambiar el origen de las abscisas. Así, por ejemplo, la geometría euclidiana estuvo presente cuando los análisis de la espacialidad toparon con aquellas propiedades que se conservan a través de los movimientos; la geometría proyectiva cuando mencionamos las isometrías de rotación y traslación; ${ }^{35}$ la

\footnotetext{
${ }_{35}$ Recordemos que una figura simétrica por rotación se obtiene si al girarla un determinado ángulo (siempre distinto de $360^{\circ}$ ) alrededor del centro de rotación C, la figura vuelve a su posición original, es decir, si el centro de giro $\mathrm{C}$ sobre el que aplicamos la rotación es el centro geométrico de la figura. Una traslación determinada por un vector (v) transforma a todo punto $\mathrm{T}$ en otro $\mathrm{T}$ ' tal que el vector
} 
geometría riemanniana cuando examinamos las variedades de dos dimensiones y la obtención de magnitudes, aunado a esto algunos ejemplos topológicos se hicieron patentes cuando nos encontramos con propiedades geométricas invariantes en la deformación continua.

Teniendo en mente lo anterior, resulta que Husserl retoma el análisis del movimiento como fenómeno primario, esto es, como un fenómeno que procede de acuerdo a la posibilidad que le brinda el campo visual, el reposo sería entonces un no-movimiento. ${ }^{36} \mathrm{El}$ cambio producido puede ser:

1).- mera deformación: cambio objetivo en la cosa, por ejemplo, la plasticidad que tienen ciertos objetos para tomar una u otra forma. Es muy probable que este tipo de modificaciones sean visibles a nivel topológico, es decir, de propiedades geométricas que son invariantes bajo deformación continua.

2).- mero cambio en la cualidad: esto remite a la posibilidad del cambio en un componente meramente cualitativo de la cosa, por ejemplo, cambios de color, aroma, etc.

$\mathrm{TT}^{\prime}=\mathrm{v}$. Por último, una reflexión es una simetría respecto de un eje de simetría E, transformando a todo punto $\mathrm{P}$ en otro punto $\mathrm{P}^{\prime}$ tal que el eje (E) es mediatriz del segmento PP'. En todas estas proyecciones no ocurre el cambio de forma y figura, sólo de orientación; en las modificaciones que analizaremos de inmediato sí ocurre un cambio de forma, figura y tamaño que las convierten en "cambios objetivos de la cosa espacial.

${ }^{36}$ Hua XVI, 364. 
3).- ambos a la vez. ${ }^{37}$

Ahora bien, la objetividad que está constituida en el espacio oculomotor visual tiene un doble modo de donación:

1) Un componente puramente visual que ofrece el campo sensorial visual.

2) Un componente de motivación cinestésica.

En tales sentidos, el reposo se puede presentar visual y cinestésicamente. En el primer caso se da a nivel meramente ocular, es decir, si no movemos nuestros ojos, y en el segundo caso se presenta cuando nuestro cuerpo no toma posición alguna con respecto al movimiento. Ambos pueden ser complementarios o contrarios. 108 Husserl recapitula lo dicho en todo este texto, cuando señala que los "conceptos fenomenológicos que son indispensables para la constitución del movimiento del cuerpoa partir del 'yo camino' como un movimiento cinestésico dentro de un movimiento de un cuerpo objetivo, a saber, el cuerpo, en el espacio objetivo" ${ }^{38}$ son:

a) El espacio visual como espacio de orientación con su punto cero y sus ejes.

b) El espacio objetivo, el espacio percibido. ${ }^{39}$

${ }^{37}$ Ídem.

${ }^{38}$ Hua XVI, 367.

${ }^{39}$ Ídem. 
Con respecto al primer punto, le corresponde, respectivamente, el reposo como fenómeno de orientación y el movimiento como fenómeno de orientación. El cuerpo está moviéndose si está cambiando de orientación, además de que puede estar en reposo en el espacio de orientación. En relación al segundo punto, esto es, al de los fenómenos de reposo y movimiento objetivo, ocurre que en nuestro cuerpo sensible no sólo percibimos el movimiento de nuestras extremidades inferiores, sino también de todo nuestro cuerpo moviéndose en el espacio de orientación, aprehendiendo el "movimiento aparente" de mi entorno, propio de los cuerpos físicos que se hallan en el espacio donde está mi cuerpo. Sobre este punto, Husserl realiza la siguiente distinción: entre nuestro movimiento y la percepción de nuestro movimiento:

1) Podemos mover nuestras manos y pies, mover partes individuales de nuestro cuerpo y percibir estos movimientos como percibo el movimiento de cualquier cuerpo externo moviéndose en un horizonte.

2) Puedo percibir cómo estos miembros corporales, de acuerdo a sus propiedades subjetivas, son movidos voluntariamente, es decir, movidos por mí. De esto no podemos tener, del movimiento en cuanto tal, constitución visual.

3) Todos los movimientos son originalmente constituidos como movimientos corporales (movimiento en el horizonte) relativos al punto cero de 
orientación, empero, el cuerpo, nuestro cuerpo, no puede percibirse como moviéndose en relación al punto cero, él es el punto cero de orientación.

4) Todo el análisis de la constitución de cualquier cuerpo espacial debe iniciar con lo fenomenológicamente primero: la orientación. Todos los cuerpos están situados en relación al "aquí", así pues, todo su cambio es un cambio según una localización del punto cero, dicho en otras palabras, es un espacio orientado.

En la transición al espacio objetivo tridimensional no se altera la figura de los objetos porque "el espacio visual es homogéneo y tiene todas las propiedades del espacio geométrico".$^{40}$ Esto ocurre porque la forma espacial (en el campo visual) es una forma euclidiana que se mantiene como tal en la constitución de niveles superiores, es un esquema formal válido para todos los cuerpos actuales y posibles dentro del plano euclidiano. ${ }^{41}$

Ya para finalizar, hay que decir que Husserl estuvo consciente del avance de las geometrías no-euclidianas a tal grado que, en cierta medida, en Cosa y espacio pueden vislumbrarse breves apuntes -aunque no del todo ordenados- sobre la posibilidad del análisis fenomenológico de las curvaturas riemannianas y de la geometría de Euler. Resulta claro que el campo visual descrito por Husserl es una multiplicidad riemanniana métricamente limitada, bidimensional y multiescalada,

\footnotetext{
${ }^{40}$ Hua XVI, 370. Excepto el ser un espacio absoluto y con profundidad.

${ }^{41}$ Hua XVI, 371.
} 


\section{ARTÍCULOS}

que como tal, es un espacio homogéneo cuyos grupos automorfos son transitivos. Con lo anterior, Husserl cree que es posible que de las superficies bidimensionales pueda constituirse un espacio homogéneo riemanniano, más aún, un espacio curvo bidimensional, ${ }^{42}$ que de cierto modo conciba a los cuerpos geométricos, en dicho espacio, como inalterados completamente, e inclusive pensarlos como conceptos límites.

La introducción de nuevas técnicas algebraicas en profunda coordinación con los descubrimiento geométricos representan un gran paso más allá de la mera “idealización" del espacio euclidiano, es decir, van más allá de verlo como la forma de axiomatización por antonomasia; según Husserl la geometría euclidiana surge como una abstracción de los campos geométricos de tres dimensiones y las geometrías no-euclidianas de $n$-dimensiones pueden ser construidas a partir del agregado de variables y fórmulas.

\section{Bibliografía}

- Claesges, Ulrich (1964), Edmund Husserls Theorie der Raumkonstitution, Martinus Nijhoff, The Hague, Netherlands.

- Fernández Beites, Pilar (1999), Fenomenología del ser espacial, Publicaciones Universidad Pontificia Salamanca, Salamanca.

${ }^{42}$ Hua XVI, 371. 
(2000), “El campo visual y su protoespacialidad subjetiva", en Escritos de Filosofía, No. 37-38, Buenos Aires, pp. 273-298.

- Holenstein, Elmar (1972), Phänomenologie der Assoziation: Zur Struktur und Funktion einer Grundprinzips der passiven Genesis bei E. Husserl. The Hague, Martinus Nijhoff.

- Husserl, Edmund (1973) [Hua XVI] Ding und Raum. Vorlesungen 1907. Hrsg. von Ulrich Claesges, Boston/Londres: Martinus Nijhoff.

\section{$\bullet$}

- - ---- (2004) [Hua XXXVIII] Wahrnehmung und Aufmerksamkeit.

Texte aus dem Nachlass (1893-1912). Hrsg. von Thomas Vongehr und Regula Giuliani. Boston/Londres: Martinus Nijhoff, 2004.

$\bullet$ (2005), Ideas relativas a una fenomenología pura y una filosofía

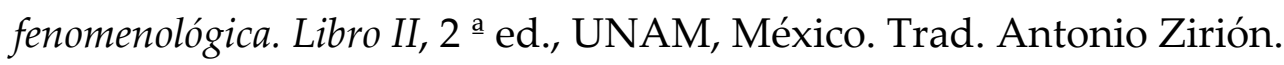

- ---------- (1997), La idea de la fenomenología, F. C.E., Madrid.Trad. Miguel García-Baró.

- Melle, Ullrich (1983),Das Wahrnehmungsproblem und seine Verwandlung in Phänomenologischer Einstellung. Untersuchungen zu den phänomenologischen Wahrnehmungstheorien von Husserl, Gurwitsch und Merleau-Ponty, Martinus Nijhoff Publishers, The Hague/Boston/Lancaster.

- Petitot, Jean, et. al. (Ed.) (2000), Naturalizing Phenomenology: Issues in Contemporary Phenomenology and Cognitive Science, Stanford University Press. 


\section{ARTÍ́CULOS}

- Rabanaque, Luis Román(1996), “El papel de la habitualidad en la constitución de la identidad personal del sujeto" en Escritos de Filosofía , Buenos Aires, No. 29-30, pp. 21-39.

- --ar- (1998), “Alteridad, cinestesia, tiempo" en Escritos de Filosofía, No. 33-34, Buenos Aires, pp. 91-107.

(2010), "Cuerpo, Cinestesia, Noema" en Selected Essays form Latin America: Traversing Multifarious Dimensions of Worldly (PHENOMENOLOGY, Vol. 2), Andre de Macedo Duarte, Rosemary Rizo-Patrón y Antonio Zirión(Ed.), Bucharest, Zeta Books/ Paris, Arghos-Diffusion.

- Serrano de Haro, Agustín (1990), Fenomenología y ontología, Madrid, España, Universidad Complutense de Madrid.

(1995), “Actos básico y actos fundados. Exposición critica de los primeros análisis husserlianos" en Anuario Filosófico, vol. XXVIII/1, Universidad de Navarra, España, pp.61-89.

- - --------(1997), “Fundamentos del análisis fenomenológico del cuerpo"en La posibilidad de la fenomenología (Ed.), Agustín Serrano de Haro, UCM, España.

la puntería, Trotta, Madrid. 
- Siksou, M., (Ed.) (2005), Symétries: symétries et asymétries du vivant, Hermés Sciences, Paris.

- Smith, Barry and Woodruft, Smith, (Eds.) (1995), The Cambridge Companion to Husserl, Cambridge University Press.

- Walton, Roberto (2005), "El análisis intencional y el acceso a la historia", en Escritos de Filosofía, Núm. 45, año XXIV, enero-diciembre, Buenos Aires, Argentina.

$\bullet$ (1993), Husserl, mundo, conciencia y temporalidad, Editorial Almagesto, Buenos Aires, Argentina. 